\title{
Economics for a creative world: a response to comments
}

\author{
ROGER KOPPL* \\ Whitman School of Management, Syracuse University, Syracuse, NY, USA \\ STUART KAUFFMAN* \\ Institute for Systems Biology, Seattle, WA, USA \\ TEPPO FELIN ${ }^{* * *}$ \\ Said Business School, University of Oxford, Oxford, UK \\ GIUSEPPE LONGO ***** \\ Centre Cavaillès, République des Savoirs, CNRS, Collège de France et Ecole Normale Supérieure Superieure, Paris, \\ France and Department of Integrative Physiology and Pathobiology, Tufts University School of Medicine, Boston, MA, \\ USA
}

\begin{abstract}
In response to Pelikan, Witt, Foster, and Colander, we reiterate our main contributions: (1) our more careful demonstration of why 'mechanistic' models have limited application, (2) our account of novelty as a system-level phenomenon, and (3) our identification of 'novelty intermediation' as important to creative economic dynamics. We also address some of the criticisms raised by the commenters. Pavel Pelikan's idea of stochastic causality does not somehow eliminate unprestateable change. We do challenge certain strong notions of universal causation, as Ulrich Witt notes, but such notions are probably best abandoned. Although, we do not repudiate mathematical modeling as our paper suggested to John Foster, we may give less scope than Foster to such methods. Finally, we point out the extreme difficulty of implementing the sort of engineering vision Colander articulates.
\end{abstract}

Those, who are strongly wedded to what I shall call 'the classical theory', will fluctuate, I expect, between a belief that I am quite wrong and a belief that I am saying nothing new. It is for others to determine if either of these or the third alternative is right.

J.M. Keynes

We are honored to receive comments from an extraordinary group of economists, all of whom are working in one way or another beyond the bounds of orthodox economics. The generally positive tone of the comments and the high level of general agreement are striking to us. However, our commenters do have

\footnotetext{
*Email: rkoppl@syr.edu

**Email: stukauffman@gmail.com

***Email: teppo.felin@sbs.ox.ac.uk

****Email: Giuseppe.Longo@ens.fr
} 
some objections. Colander thinks we are too hard on mainstream economics, while Foster thinks we are too soft. Foster objects that we seemingly reject the use of mathematics in economics entirely, and Witt seems to think our paper veers into a kind of theoretical nihilism. Pelikan thinks that economists 'may not know what to do' with our rather high-level generalities. Finally, there is some question of how innovative our argument might be. Although, our commenters were generally favorable to our analysis and always kind, we were sometimes reminded of Henry Hazlitt's criticism of Keynes' General Theory: 'What is original in the book is not true; and what is true is not original' (Hazlitt, 1983, p.3).

We think that our analysis does make a contribution if it is correct. Before responding to individual comments, we would like to restate what we think our main contributions to have been.

First, our explanation of why 'mechanistic' models are generally inappropriate in economics may be more careful and satisfactory than previous efforts.

As we tried to indicate in our paper, we use the potentially elastic word 'mechanistic' only for models in which the dynamics are represented as 'the unfolding of a process fully described, up to a stochastic error term, by a master set of equations or an evolution function'. We show that the phase space is not stable and cannot be stable, which has not quite been done previously as far as we can tell. We noted the similarity of our analysis to Shackle's discussion of the listing problem. But we get unlistability from a close internal critique of physics-based models rather than considerations of the creativity of human decision-making. (See also Felin et al., 2014) Strictly speaking, therefore, our discussion is applicable only to modeling strategies that require a stable phase space.

Second, and relatedly, we show how novelty emerges even without ex nibilo acts of 'creation' by gods or persons. Novelty production occurs at the systems level in our analysis. As far we can tell this path to novelty and unlistability in economics has not been taken before.

Finally, we develop the concept 'novelty intermediation'. While we have stuck mostly to a metatheoretic framework, our discussion of novelty intermediation was meant to show that our framework matters for applied work. We noted that Potts (2012) and Earl and Potts (2004) gave us 'the first clear and reasonably complete statements of the basic idea'. Our treatment advances upon theirs, however, because we identify the structural element in the system that makes it possible for novelty intermediaries to emerge. With Potts (2012) and Earl and Potts (2004), the idea is that certain businesses know about recent innovations that have already taken place, whereas the retail consumer does not. These businesses inform the consumer by suggesting certain combinations or offering products that exhibit certain combinations. In our analysis, instead, the intermediary knows what combinations of inputs may generate new discoveries. 
We turn now to some remarks of our individual commenters. Space constraints prevent us from going into some of the issues as deeply as we might otherwise desire.

Pelikan and Witt both question our rather strong claims about causality. Pelikan thinks we neglect 'stochastic causality'. Witt upbraids us for denying the 'principle of causation'. It is a bit difficult to address these serious concerns in part because space limitations prevent each author from fully specifying what these terms mean. Thus, we are only too keenly aware of the risk that we might unintentionally misconstrue their arguments. Such a danger is well illustrated by Hodgson's (2004, pp. 57-65) lucid discussion of causality and of 'the ambiguous bogeys of mechanism and determinism'. Like Bunge (1959), he notes the diversity of meanings that may attach to terms such as 'causality' and 'determinism'. Bunge's (1959) classic also notes the tension between theories such as those of Locke, Berkley, Hume, and Kant, that view 'causation as a mental construct, as a purely subjective phenomenon' and is own view that 'causation has an ontological status', though one that 'raises epistemological problems' (pp. 5-6). In spite of the dangers of miscommunication, we will address the concerns of both Pelikan and Witt.

When Pelikan invokes 'stochastic causality' he may have in mind something like the 'probabilistic causality' described by Suppes (1970) and Cartwright (2006). In this theory, C 'causes' $\mathrm{E}$ if the conditional probability of E given C is greater than the conditional probability of $\mathrm{E}$ given not-C. This and similar ideas may seem to conflate epistemology and ontology. However that may be, our purposes suggest a very different sort of response. The similar definitions given by Suppes and Cartwright both require us to have 'a state description over a "complete" set of confounding factors' (Cartwright, p. 58). In a footnote, Cartwright says, 'The scare quotes are around "complete" because it is a difficult notion to define'. This wise remark suggests why our 'reasoning about the nonalgorithmic nature of economic change' may not be 'significantly weakened' by notions of 'stochastic causality'. Such notions would seem to depend on a stateable set of possibilities such that a probability measure may be defined. But if our vision of creative dynamics is about right, a probability measure cannot generally be defined unless possible events are described only in very general terms. For similar reasons, we doubt that the notion of 'stochastic algorithm' mentioned by Pelikan would much alter our analysis.

We might evade Witt's criticism of our views on 'law' and 'cause' by pointing out that we have criticized only a very narrowly circumscribed set of ideas on law and cause. Our repudiation of 'entailing laws' leads us to reject the notion that the future is somehow wholly contained in the past. We are weaving our way into the future, not unrolling a tapestry that was completed long ago. We are conscious of C. S. Peirce's remark, 'The great principle of causation which we are told, it is absolutely impossible not to believe, has been one proposition at one period of history and an entirely disparate one [at] another and is still a 
third one for the modern physicist. The only thing that has stood ... is the name of it' (Peirce, 1992, p. 197). Witt seems to recognize the issue when he says, 'The problem seems to be that the notion of a 'law' can be given different meanings'. We explicitly note, as Witt acknowledges, that 'cause and effect still operate in the econosphere'.

We could dodge Witt's criticism in this way, but we will not. We have indeed taken a swipe at notions to the effect that everything has a cause, or at least a cause that we can identify in advance. We think it is noteworthy that our position emerges from a careful look at one relatively narrow class of models rather than general considerations of 'cause' or 'law'. In any event, the conclusion that economic change is not algorithmic does compromise at least some notions of the 'principle of causation'. In this sense it is, perhaps, 'radical'. We are not alone in chipping away at such notions. Chaitin has interpreted algorithmic information theory to imply that 'certain mathematical facts are true for no reason' (Chaitin, 2006, pp. 77-78). Citing Bell's inequalities, Filk and von Müller have noted that 'Leibniz' principle of sufficient reason does not hold in quantum theory' (Filk and von Müller, 2009, p. 64). If we are going to hold fast to strong notions of universal causation, it seems, we will have to ignore or deny some important results in mathematics and physics.

In physics, we know what we mean by cause. In classical physics, for example, force is mass times acceleration. In chemistry too we know, at least for classical chemical reaction systems. In quantum mechanics 'cause' is less clear. And in evolution it may be even less clear. Certainly, we would all say that the tiger biting the gazelle 'causes' its death. But Longo et al. (2012) deny entailing laws for evolution. If 'causal mechanism' and 'cause' require entailing laws, then there is no causal mechanism for evolution as a whole. In the social sciences, where responsible free will and consciousness may play a role, what should we mean by 'cause'? Are preferences (utility functions) 'causes'? Beyond that, our claim is that enablement is real. We might say that finding a loophole in a law (as it were) enables but does not cause the new strategy that may emerge and endure. The mainframe computer's success did not cause the personal computer but it did (with the invention of the chip) enable the PC whose wide sale did not cause but did enable the emergence of word processing, and so on to the web and to selling on the web. Each of these innovations was enabled-but-not-caused by what had come earlier.

Our biggest disagreement with Foster concerns his characterization of us as 'non-economists'! This is perhaps technically true of Kauffman, Felin (more or less), and Longo - at least in terms of their primary training and disciplinary background. But Koppl's graduate training was in economics. Indeed, Koppl is usually considered something of an 'Austrian', which might make him a heterodox economist (Koppl, 2006). And his previous co-authors have included economists from other heterodox schools. Kauffman and Felin have also respectively contributed to economics: Kauffman to evolutionary economics and 
Felin to the domain of organizational economics. Space limitations drove us to make only some references to these literatures, but not because we were unaware of them. Furthermore, Foster thinks we are 'too quick to dismiss mathematics as a useful tool in understanding economic evolution'. Perhaps. But we did express a favorable disposition to several mathematical tools, including the one Foster seems to like best, namely, mathematical network theory. But part of the problem is that even heterodox economics, including mathematized versions, are often built on a particular brand of theorizing (e.g., Nelson and Winter, 1982) which cannot meaningfully account for the emergence of novelty (Felin and Foss, 2011).

Colander says we are too hard on the mainstream and Foster says we are too soft. Those two very different opinions give us hope that we may have hit the Goldilocks point: neither too hard nor too soft, but just right. Colander says the 'reasonable mainstream' already has a 'skeptical attitude toward economic experts'. If so, some well-respected names may fall outside the 'reasonable mainstream'. For example, Reis (2013) has said, 'The central bank may be more effective in technical tasks where ability to incorporate quickly changing knowledge is more important than effort at meeting the goals in a strict mandate' set down by the elected representatives of the people (p. 19). This defense of central bank independence expresses little skepticism of economic experts. Policy prescriptions emerging from some of the network-theoretic literature on financial-market contagion (Acharya, 2009; Beale et al., 2011; Caccioli et al., 2011; Gai et al., 2011; Haldane and May 2011; and Yellen, 2009, 2011) also seems to reflect a sanguine view of economic expertise. Acharya, for example, says it is 'paramount' that banks report their 'portfolio compositions' to 'the regulator' so that it can compute systemic risk and 'determine the collective risk capital charge for each bank' $(2009$, p. 248). But he does not ask whether this procedure gives too much power to economic experts.

Colander says, 'the reasonable mainstream's commitment to formal scientific methodology requires any theoretical considerations to have all i's dotted and t's crossed before these policies become part of the academic discourse'. But at least two Nobel laureates have expressed a very different attitude. Akerlof and Shiller (2009) compare the policymaker to the Cat in the Hat who, they remind us, 'tried Plan A, and then Plan B, and then Plan C, and then even Plan D'. We should emulate the Cat, they say, and 'go on down the alphabet, until we find something' that works (location 263). This zeal to 'go on down the alphabet' is hardly the slow and cautious attitude of someone who wants all i's dotted and t's crossed. Colander would surely object that he explicitly referred to science and not to policy, which is always an art (Colander, 1992), especially in times of crisis. Yes. But the policy experiments advocated by Akerlof and Shiller seem largely unconstrained by theory, which calls into question the hyper-conservatism of theory Colander describes. The theoretical conservatism of the mainstream (in macroeconomics at least) would not seem to be a point 
in its favor. The tools of mainstream macroeconomic theory have not been evolving in the right direction. The mainstream has been committed to methods that implicitly deny the creativity and dynamism of the real system. It is as if the mainstream is saying that we need to do more work on the theory of ox carts if we are to hope for progress in understanding rocket ships! This hyperconservatism of macroeconomic theory might be changing in the wake of the crisis, but if so the center of gravity has not yet moved very far.

Finally, we would like to address Colander's important remarks about engineering. Colander has long emphasized the lost art of economics (Colander, 1992). Economists have lost sight of the art of economics as understood by John Neville Keynes. Beside the 'positive science of political economy which is concerned purely with what is' and the 'ethics of political economy', which 'seeks to determine economic ideals', there is the 'art of political economy, which seeks to formulate economic precepts' (Keynes, 1917, p. 36). These 'precepts' are 'rules' or 'maxims' through which 'given ends may best be obtained' (Keynes, 1917, p. 32). This 'art' is what Colander has in mind when he tells us to think of applied economics as engineering.

It seems hard to question the desirability of adopting 'the strategy for causing the best change in a poorly understood or uncertain situation'. But what is that strategy? On this vital question, we do not agree amongst ourselves. Should we support the approach of 'complex engineered systems' in which 'performance characteristics emerge from the implemented system rather than existing in a fully specified form ex ante' (Koppl et al., 2010)? Or is a more urgent collective response is required, as Longo believes, particularly considering the damage humans may be doing to the ecosystem? Perhaps activities such as the production of new chemicals that might present dangers such as endocrine disruption (a major challenge now) require the dynamic proposal of rules forbidding this, directing that, and canalizing the other. Perhaps, the engineering challenge is how to make economic projects in a continually changing frame.

Whether 'the answer' is something about markets, something about democracy, or something else, our vision of creative dynamics shows how hard Colander's engineering task is. It shows how hard it is to know what is 'the strategy for causing the best change'. To have a best strategy, you need a partial order with a maximum and, therefore, some sort of pregiven space, which is exactly what we deny. Our analysis challenges strong notions of optimality in economics and (following Longo et al., 2012) biology. The front legs of a kangaroo, elephant, or opossum are not optimal. They are the outcome of the one possible evolutionary trajectory for tetrapod front legs that happened to have been followed so far. Individuals and organizations may have preferences, which may imply a kind of optimality of individual choices. One may try, as it were, to become a kangaroo, though it may not work. But notions of optimality do not easily apply to the creative dynamics of the biosphere and the econosphere. 


\section{References}

Acharya, V. V. (2009), 'A Theory of Systemic Risk and Design of Prudential Bank Regulation', Journal of Financial Stability, 5(3): 224-255.

Akerlof, G. A. and R. J. Shiller (2009), Animal Spirits: How Human Psychology Drives the Economy, and Why It Matters for Global Capitalism, Princeton, NJ: Princeton University Press.

Beale, N., D. G. Rand, H. Battey, K. Croxson, R. M. May, and M. A. Nowak (2011), 'Individual Versus Systemic Risk and the Regulator's Dilemma', PNAS Early Edition, http://www.pnas.org/content/early/2011/07/13/1105882108.full.pdf+html (accessed 3 November 2011).

Bunge, M. (1959), Causality: The Place of the Causal Principle in Modern Science, Cambridge, MA: Harvard University Press.

Caccioli, F., T. A. Catanach, J. D. Farmer (2011), 'Heterogeneity, Correlations and Financial Contagion', manuscript, http://arxiv.org/pdf/1109.1213v1 (accessed 20 September 2011).

Cartwright, N. (2006), 'Where is the Theory in our 'Theories' of Causality?', Journal of Philosophy, 53(2): 55-66.

Chaitin, G. (2006), 'The Limits of Reason', Scientific American, 294(3): 74-81.

Colander, D. (1992), 'The Lost Art of Economics', Journal of Economic Perspectives, 6(3): 191-198.

Earl, P. E. and J. Potts (2004), 'The Market for Preferences', Cambridge Journal of Economics, 28(4): 619-633.

Felin, T. and N. Foss (2011), 'The Endogenous Origins of Experience, Routines, and Organizational Capabilities: The Poverty of Stimulus', Journal of Institutional Economics, 7(2): 231-256.

Felin, T., S. Kauffman, R. Koppl, and G. Longo (2014), 'Economic Opportunity and Evolution: Beyond Bounded Rationality and Phase Space', Strategic Entrepreneurship Journal, forthcoming.

Filk, T. and A. Müller (2009), 'Quantum Physics and Consciousness: The Quest for a Common Conceptual Foundation', Mind and Matter, 7(1): 59-79.

Gai, P., A. Haldane, and S. Kapadia (2011), 'Complexity, Concentration and Contagion', Journal of Monetary Economics 58(5): 453-470.

Haldane, A. and R. M. May (2011), 'Systemic risk in banking ecosystems', Nature 469(7330): 351-355.

Hazlitt, H. (1983), "Introduction," to Hazlitt, Henry (ed.), The Critics of Keynesian Economics, Lanham, MD: University Press.

Hodgson, G. (2004), The evolution of institutional economics: Agency, structure and Darwinism in American institutionalism, London: Routlege.

Keynes, J. N. (1917), The Scope and Method of Political Economy, 4th ed. Reprinted in 1963 by A. M. Kelley, Booksellers, New York.

Koppl, R. (2006), 'Austrian Economics at the Cutting Edge', Review of Austrian Economics, 19(4): 231-241.

Koppl, R., A. A. Minai, and H. Sayama (2010), 'Epistemic Engineering', NSF SBE 2020 White Paper. Available at http://www.nsf.gov/sbe/sbe_2020/submission_detail.cfm? upld_id=277 (accessed 15 October 2014). 
Longo, G., M. Montévil, and S. Kauffman (2012), 'No Entailing Laws, but Enablement in the Evolution of the Biosphere', Physics ArXiv, 1201.2069v1: http://arxiv.org/abs/1201.2069.

Nelson, R. R. and S. G. Winter (1982), An Evolutionary Theory of Economic Change, Cambridge, MA: Belknap Press/Harvard University Press.

Peirce, C. S. (1992), Reasoning and the Logic of Things: The Cambridge Conferences Lectures of 1898, Cambridge and London: Harvard University Press.

Potts, J. (2012), 'Novelty-Bundling Markets', in David E. Andersson (ed.), The Spatial Market Process, Advances in Austrian Economics, vol. 16, Bradford: Emerald Publishing Group.

Reis, R. (2013), 'Central Bank Design', Journal of Economic Perspectives, 27(4): 17-43.

Suppes, P. (1970), A Probabilistic Theory of Causality, Amsterdam: North-Holland Publishing Company.

Yellen, J. (2009), 'A Minsky Meltdown: Lessons for Central Bankers', Presentation to the 18th Annual Hyman P. Minsky Conference on the State of the U.S. and World Economies. http://www.frbsf.org/news/speeches/2009/0416.pdf (accessed 11 November 2009).

Yellen, J. L. (2011), 'Macroprudential Supervision and Monetary Policy in the Post-Crisis World', Business Economics, 46(1): 3-12. 